mansasa

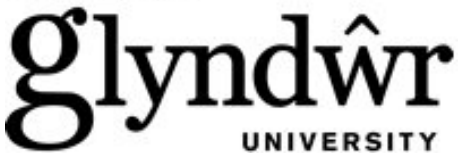

Glyndŵr University

Glyndŵr University Research Online

Aeronautical Engineering

Engineering

6-1-2006

\title{
Investigation of the microwave curing of the PR500 epoxy resin system
}

Mark Wallace

Sowerby Research Centre

David Attwood

Manchester Materials Science Centre

Richard Day

GlyndwrUniversity, r.day@glyndwr.ac.uk

Frank Heatley

University of Manchester

Follow this and additional works at: http://epubs.glyndwr.ac.uk/aer_eng

Part of the Aeronautical Vehicles Commons, Applied Mechanics Commons, Catalysis and Reaction Engineering Commons, Engineering Mechanics Commons, Materials Chemistry Commons, Mechanics of Materials Commons, Other Aerospace Engineering Commons, Other Chemical Engineering Commons, Other Civil and Environmental Engineering Commons, Other Engineering Science and Materials Commons, Other Materials Science and Engineering Commons, Physics Commons, Polymer and Organic Materials Commons, Polymer Science Commons, Structural Materials Commons, and the Structures and Materials Commons

\section{Recommended Citation}

Wallace, M., Attwood, D., Day, R. J., Heatley, F. (2006) 'Investigation of the microwave curing of the PR500 epoxy resin system. Journal of Materials Science, Volume 41 No.18, pp. 5862-5869

This Article is brought to you for free and open access by the Engineering at Glyndŵr University Research Online. It has been accepted for inclusion in Aeronautical Engineering by an authorized administrator of Glyndŵr University Research Online. For more information, please contact d.jepson@glyndwr.ac.uk. 


\title{
Investigation of the microwave curing of the PR500 epoxy resin system
}

\begin{abstract}
Microwave heating has been used to cure a resin system, PR500 (3M). The same resin has been cured using a conventional oven. The cured resins have been compared using a number of techniques including modulated differential scanning calorimetry (MDSC), dynamic thermal analysis, infrared spectroscopy (IR) and solidstate NMR spectroscopy. The reaction path appears to be slightly different depending upon the nature of the heating. The epoxy-amine reaction occurs to a greater extent than the epoxy-hydroxyl reaction in the microwave cured resin compared to the thermally cured resin. The dielectric properties for the thermally and microwave cured materials were measured for degrees of cure greater than $75 \%$ and over this range are similar for materials cured by the two techniques and thus not sensitive to this change. Broadening of the glass transition for microwave-cured epoxy resins was observed. Since the IR and solid-state NMR results show small differences as does the DMA behaviour of materials cured using the two routes the broadening is attributed to a difference in network structure
\end{abstract}

\section{Keywords}

Microwave curing, Epoxy resin, Reaction path, Infrared spectroscopy, Solid-state NMR, Differential scanning calorimetry, Dynamic mechanical analysis

\section{Disciplines}

Aeronautical Vehicles | Aerospace Engineering | Applied Mechanics | Catalysis and Reaction Engineering | Chemical Engineering | Chemistry | Engineering | Engineering Mechanics | Engineering Science and Materials | Materials Chemistry | Materials Science and Engineering | Mechanical Engineering | Mechanics of Materials | Other Aerospace Engineering | Other Chemical Engineering | Other Civil and Environmental Engineering | Other Engineering Science and Materials | Other Materials Science and Engineering | Physics | Polymer and Organic Materials | Polymer Science | Structural Materials | Structures and Materials

\section{Comments}

Copyright (C) 2006 Springer This version of the article is the authors final draft post-refereeing. The article was published in the Journal of Materials Science published by Springer in 2006. The original publication is available at http://dx.doi.org/10.1007/s10853-006-0321-3 on the publishers website www.springerlink.com 


\title{
INVESTIGATION OF THE MICROWAVE CURING OF THE PR500 EPOXY RESIN SYSTEM
}

\author{
Mark Wallace ${ }^{1}$, David Attwood ${ }^{1}$, Richard J. Day ${ }^{2}$, and Frank Heatley ${ }^{3}$ \\ ${ }_{1}^{1}$ Sowerby Research Centre, British Aerospace Operations Ltd., Filton, \\ Bristol BS12 7QW, U.K. \\ ${ }^{2}$ Manchester Materials Science Centre, UMIST, Grosvenor Street, Manchester M1 7HS, U.K. \\ ${ }^{3}$ Department of Chemistry, University of Manchester, Oxford Road, Manchester M13 9PL, \\ U.K.
}

SUMMARY: Microwave heating has been used to cure a resin system, PR500 (3M). The same resin has been cured using a conventional oven. The cured resins have been compared using a number of techniques including modulated differential scanning calorimetry, dynamic thermal analysis, infrared spectroscopy and solid-state NMR spectroscopy. The reaction path appears to be slightly different depending upon the nature of the heating. The epoxy-amine reaction occurs to a greater extent than the epoxy-hydroxyl reaction in the microwave cured resin compared to the thermally cured resin. The dielectric properties for the thermally and microwave cured materials were measured for degrees of cure greater than $75 \%$ and over this range are similar for materials cured by the two techniques and thus not sensitive to this change. Broadening of the glass transition for microwave-cured epoxy resins has been widely observed previously. Since the IR and solid-state NMR results show small differences as does the DMA behaviour of materials cured using the two routes the broadening is attributed to a difference in network structure.

KEYWORDS: Microwave curing, epoxy resin, reaction path, infrared spectroscopy, solidstate NMR, differential scanning calorimetry, dynamic mechanical analysis 


\section{INTRODUCTION}

Microwave heating can reduce the processing times for a range of materials very substantially. Typical cure times for thermosetting resins are reduced from hours to tens of minutes or less through the use of microwave rather than conventional curing. Nightingale and Day [1] cured carbon/ epoxy composites using a microwave oven in approximately $20 \%$ of the time required for thermal cure. Zainol, Day and Heatley [2] and Zainol and Day [3] have reduced the time for full cure of two bismalimide resins from 24 hours, the duration of the manufacturers recommended cure schedule, to less than twenty minutes. There is thus potential for savings to be made in commercial manufacture through shorter cure cycles and, since the microwave energy is largely concentrated on the sample, greater efficiency. This in turn could lead to other savings. For example, the higher throughput reduces the number of facilities required thus leading to a reduction in capital equipment costs.

If microwave processing of resins is to be usefully employed in the production of components then it is important to understand the structure and properties of the cured resins. Changes in curing chemistry are possible and this could affect mechanical properties, moisture uptake and resin degradation properties. This is an area where there has been controversy in the literature [4-6]. In bismalimide resins [2-3] the chemical reactions during microwave and thermal cure have been shown to be identical. There are very many studies of different epoxy resin systems. Nesbitt, Suckley and Day [7], for instance, have studied the LY5052/HY5052 system (Advantico) which is an epoxidised novolak resin with an amine hardener and observed some differences between the chemical reactions during microwave and thermal cure.

A number of researchers have explored the glass transition of a number of epoxy resin systems and their findings vary significantly. It has, for instance, been found that the glass transition temperature in a microwave cured epoxy resin was higher than for the same system when conventionally cured [8]. There are several reports in the literature which show that the glass transition in some epoxy systems is broader when the resin has been microwave cured compared to when the resin has been conventionally cured[5-7, 9-10].

In the present work an epoxy system, PR500 from 3M (also known as SP-500 resin), has been cured using both conventional and microwave heating. Materials cured by these two routes have been compared using modulated differential scanning calorimetry (MDSC), dynamic mechanical analysis (DMA), infrared spectroscopy (IR), dielectric property measurement and solid state NMR spectroscopy. 
PR500 is known to be a mixture of three fluorene-based materials [11]:

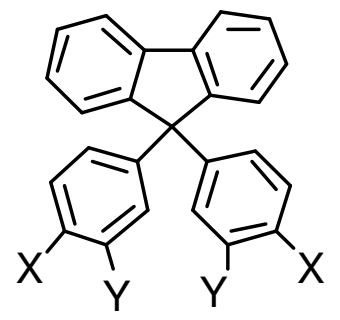

$1 \mathrm{X}=-\mathrm{NHCH}_{3}, \mathrm{Y}=\mathrm{H}$

$2 \mathrm{X}=\mathrm{NH}_{2}, \mathrm{Y}=\mathrm{Cl}$

$3 \mathrm{X}=-\mathrm{O}-\mathrm{CH}_{2}-\mathrm{CH}_{\mathrm{O}}^{\mathrm{C}}-\mathrm{CH}_{2}, \mathrm{Y}=\mathrm{H}$

Component 1 is a disecondary amine giving a linear segment in the network whereas component 2 is a diprimary amine generating network crosslinks.

\section{EXPERIMENTAL}

\section{Thermal Cure}

Samples were cured isothermally in a conventional oven at $180{ }^{\circ} \mathrm{C}$ for $90,100,130,160$ and 180 minutes.

\section{Microwave Cure}

A conventional multimode commercial microwave oven (Hinari MX717TC) was used. Within multimode microwave cavities the electric field and thus heating is not uniform. Day, Yau and Hewson [9] have shown that one method for assessing the heating pattern is to place a sheet of partially cured resin in the cavity and to post cure for a short time. The resin becomes darker where it has been heated and thus the position of hot spots within the cavity can be identified visually from the cured resin sheet. This is, however, an approximate approach since the heating pattern in a multimode cavity depends upon the load. In the present work, thin plaques of a room temperature curing epoxy resin system (DER 332/Crayamd 140) were used [5,6]. The resin was cast onto the turntable of the microwave and also onto a glass plate that was set to the same height. After heating, variations in the colour of the resin were observed and this allowed selection of a suitable position in the oven where uniform curing of the resins might be expected. As a result of this investigation, samples of dimension $50 \times 50 \times 5 \mathrm{~mm}$ in silicone rubber moulds were subsequently placed in the centre of the turntable. Initial experiments resulted in a rapid temperature rise in the 
sample. To reduce the heating of the sample, the oven's normal rating of $800 \mathrm{~W}$ was reduced by introducing an additional $0.95 \mu \mathrm{F}$ capacitor between the transformer and magnetron. By measuring the power using the rise in temperature of a beaker of water, it was found that the introduction of the extra capacitor lead to the power absorbed by the water being reduced to $400 \mathrm{~W}$. The power absorbed by the sample was further reduced by the use of a load consisting of $500 \mathrm{ml}$ of $1 \%$ sodium chloride solution in water. The power at the sample position, as measured using water, was then reduced to $30-40 \mathrm{~W}$. Since the power levels were measured using a water load and not with the resin they are not accurate as the power lost to the sample, load and cavity will depend upon their relative loss factors. As the loss factor of water was larger than that of the sample this is likely to be an overestimate of the power absorbed by the sample. A further problem is that the introduction of the water load into the cavity may lead to water absorption by the resin during cure. In order to reduce the possibility of this occurring and affecting the curing reactions the sodium chloride solution was cooled to a few degrees above freezing prior to use and replaced every ten minutes during cure. The rise in temperature was monitored and was found to be approximately $10{ }^{\circ} \mathrm{C}$ after ten minutes. The temperature reached when the load was replaced was thus approximately room temperature and was considered too small to give appreciable evaporation of the solution.

As noted above significant reductions in the cure times of a number of thermosetting resins have been achieved by using microwave heating. The objective of this work was not to minimise the cycle time, but to compare thermally and microwave cured samples. Hence the cure schedule for the PR500 resin in the microwave oven was 180 minutes with the sodium chloride solution load (approximately $40 \mathrm{~W}$ to the sample) followed by $0,5,7.5,10$ and 15 minutes with no sodium chloride solution load (approximately $400 \mathrm{~W}$ to the sample).

\section{Differential Scanning Calorimetry}

Conventional differential scanning calorimetry (DSC) was used to obtain the enthalpy of cure for the as-received resin. The residual enthalpy for the cured samples and the glass transition temperature, $T_{\mathrm{g}}$, were measured by modulated DSC (MDSC) using a Mettler-Toledo TA8000 system. The residual enthalpy was measured using samples with weights in the range 1$20 \mathrm{mg}$ sealed in $40 \mathrm{ml}$ aluminium pans. For the conventional DSC samples were heated from 50 to $350{ }^{\circ} \mathrm{C}$ at $2,5,10$ and $20{ }^{\circ} \mathrm{C} \mathrm{min}-1$. MDSC was performed in the temperature range 50- 
$350{ }^{\circ} \mathrm{C}$. A ramp at $5{ }^{\circ} \mathrm{C}$ min $^{-1}$ with a superimposed alternating signal of $\pm 1{ }^{\circ} \mathrm{C}$ was used. $T_{\mathrm{g}}$ was determined from the onset of the second order change in the storage part of the heat capacity. The enthalpy of residual cure was obtained from the loss part of the heat capacity by integration of the area of the exotherm. A spline baseline was used since the actual baseline was not horizontal . From the enthalpy the degree of cure, $\alpha$, was calculated using

$$
\alpha=1-\frac{\Delta H_{\mathrm{c}}}{\Delta H_{\mathrm{u}}}
$$

where $\Delta H_{\mathrm{c}}$ is the residual curing enthalpy of a partial cured sample of resin and $\Delta H_{\mathrm{u}}$ is the curing enthalpy of the as-received resin.

\section{Dynamic Mechanical Analysis}

A Netzch DMA 242 instrument in dual cantilever mode was used to obtain the dynamic mechanical data. The samples were heated from -160 to $300{ }^{\circ} \mathrm{C}$ at a rate of $5{ }^{\circ} \mathrm{C} \mathrm{min}-1$. The magnitude of the displacement was $30 \mu \mathrm{m}$ and the frequency $1 \mathrm{~Hz}$.

\section{Infrared Spectroscopy}

Fourier transform infrared (FTIR) spectra were obtained from the cured resin using a Perkin Elmer PE2000 spectrometer. A fine file was used to obtain powder which was then pressed into a $\mathrm{KBr}$ disc.

\section{Dielectric Measurement}

The cavity perturbation method was used to obtain the dielectric constant and loss of the partially cured resin samples as a function of degree of cure. Small cubes of the resin were cut from the cured plaques. The properties were obtained at a frequency of $2.45 \mathrm{GHz}$, this being the operating frequency that the microwave oven. A TM111 brass cavity was used for the measurements. The samples were placed on a low loss polyethylene foam support in the centre of the cavity. A calibrated Hewlett Packard HP 8753 vector network analyser was used to measure the resonant frequency and $\mathrm{Q}$ value of the cavity with and without the sample. The support was present for both measurements. From this data the real, $\varepsilon^{\prime}$, and imaginary, $\varepsilon^{\prime \prime}$, parts of the complex dielectric constant were obtained using the following formulae [4]:

$$
\varepsilon^{\prime}=1+\frac{\left(\omega_{0}-\omega_{\mathrm{s}}\right) V_{\mathrm{cav}}}{2 \omega_{0} V_{\mathrm{sam}}}
$$


and

$$
\varepsilon^{\prime \prime}=\frac{1}{4}\left(\frac{1}{Q_{0}}-\frac{1}{Q_{\mathrm{s}}}\right) \frac{V_{\mathrm{cav}}}{V_{\mathrm{sam}}}
$$

where $\omega_{0}$ is the resonant frequency of the empty cavity, $\omega_{\mathrm{S}}$ is the resonant frequency of the cavity with the sample inserted, $Q_{0}$ is the quality factor of the empty cavity, $Q_{\mathrm{s}}$ is the quality factor for the loaded cavity, $V_{\text {cav }}$ is the volume of the empty cavity and $V_{\text {sam }}$ is the volume of the sample.

\section{Solid State NMR Spectroscopy}

A Varian Associates Unity 300 spectrometer equipped with Doty Scientific Inc. probes was used to obtain ${ }^{13} \mathrm{C}$ NMR spectra from two of the samples. Thermal and microwave cured resins, both with degrees of cure of approximately 90\%, were powdered and packed into $7 \mathrm{~mm}$ O.D. alumina or zirconia rotors. The approximate sample mass was $0.5 \mathrm{~g}$. Spectra were acquired using cross-polarization/magic-angle spinning (CP/MAS) at several spin rates in the range 3.3 to $4.5 \mathrm{kHz}$ to identify chemical shielding anisotropy (CSA) spinning sidebands. The RF field strengths were $36 \mathrm{kHz}$ for cross-polarization and $45 \mathrm{kHz}$ for the dipolar decoupling field. The CP contact time was $1 \mathrm{~ms}$ and the recycle time was $5 \mathrm{~s}$. For assistance in spectrum assignment, a spectrum of the microwave cure was run using the dipolar dephasing (DD) technique whereby acquisition of the spectrum with proton decoupling is delayed for a short time to allow the ${ }^{13} \mathrm{C}$ signals to decay under the influence of ${ }^{13} \mathrm{C}-{ }^{1} \mathrm{H}$ dipole-dipole-coupling. The liquid state spectrum of the uncured resin was also used to aid the assignments. 


\section{RESULTS AND DISCUSSION}

\section{Differential Scanning Calorimetry}

The enthalpy for cure of the as-received resin was found to be $210 \mathrm{~J} \mathrm{~g}^{-1}$. This figure was used for subsequent calculations of the degree of cure. Figure 1 shows the $T_{\mathrm{g}}$ as a function of degree of cure. In the later stages of cure the glass transition temperatures for the microwave samples appear higher than for the conventionally thermally cured materials. The temperature of the microwave cured samples was not recorded and it is possible that they were cured at a higher temperature which would explain the higher $T_{\mathrm{g}}$ observed for them. For the thermally cured samples the glass transition could be readily identified. For the microwave cured samples two separate transitions appeared to be present. The difference between the beginning and end temperature of the glass transition is plotted against the degree of cure in figure 2. The width of the transition was always greater for the microwave cured samples than for the thermally cured samples at a given degree of cure, and as full cure was approached, the width of the transition decreased for samples cured by both methods. This is consistent with the previous reports indicating that $T_{\mathrm{g}}$ in microwave cured samples is broadened [5-7,9-10].

\section{Dynamic Mechanical Analysis}

DMA was used for two reasons in this study, first to investigate whether the materials had been uniformly cured and second to provide comparison between the microwave and conventionally cured resin. For the latter purpose strips were taken across the width of both microwave and conventionally cured plaques. There was a variation in the glass transition temperature of $\pm 4{ }^{\circ} \mathrm{C}$ for thermal cure and $\pm 10{ }^{\circ} \mathrm{C}$ for microwave cure. The cured plaques were uniformly coloured, again suggesting that they were uniformly cured. DMA traces for the microwave and thermally cured resin are shown in figures $3 \mathrm{a}$ and $3 \mathrm{~b}$, respectively. These show that there are differences in the materials produced using the two heating techniques. Figure 3a shows a prominent secondary peak in $\tan \delta$ at approximately $-75{ }^{\circ} \mathrm{C}$ of comparable magnitude to the $\tan \delta$ peak at approximately $80{ }^{\circ} \mathrm{C}$. In the thermally cured sample (figure 3b) the $\tan \delta$ peak at $-75^{\circ} \mathrm{C}$ is of much lower magnitude than the transition at $80{ }^{\circ} \mathrm{C}$. The tan $\delta$ peak at approximately $-75{ }^{\circ} \mathrm{C}$ is associated with the crankshaft motion of the $-\mathrm{O}-\mathrm{CH}_{2}-$ $\mathrm{CH}(\mathrm{OH})-\mathrm{CH}_{2}$ - segments which are formed by the reaction between the amine and epoxy 
groups [12]. The results suggest that the epoxy-amine reaction occurs to a greater extent in the conventionally processed materials.

\section{Infrared spectroscopy}

Figure 4 shows the FTIR spectra obtained from thermally cured (lower trace) and microwave cured (upper trace) samples. The samples were both approximately $90 \%$ cured. The spectra appear to be very similar but on close examination it was clear that there were differences in the heights of the amine and hydroxyl group peaks. The relative heights are presented in Table 1. In order to aid the comparison and to correct for the effects of sample size the intensities have been ratioed against those for an aromatic $\mathrm{CH}$ band at $3036 \mathrm{~cm}^{-1}$. This peak was selected because it is known not to be involved in any of the chemical reactions that take place during curing [13]. The amine and hydroxyl group bands are more prominent for the thermally cured sample than for the microwave cured one. This suggests that the reaction between the epoxy and amine groups occurs to a greater extent in the microwave curing process than the epoxy- hydroxyl reaction. This is consistent with the DMA results.

\section{Solid State NMR}

Figure 5(a) and (b) show the ${ }^{13} \mathrm{C} \mathrm{CP/MAS} \mathrm{NMR} \mathrm{spectra} \mathrm{of} \mathrm{the} \mathrm{thermally} \mathrm{and} \mathrm{microwave}$ cured samples, respectively. The chemical shift scale was referenced by setting the most intense aromatic peak to $128 \mathrm{ppm}$ as found in the solution-state spectrum of PR500 in $\mathrm{CDCl}_{3}$. The spectra of both samples were similar in form but there were differences in detail. In $\mathrm{CDCl}_{3}$, the original PR500 resin showed intense peaks at 45 and $50 \mathrm{ppm}$ arising from the epoxide $\mathrm{CH}_{2}$ and $\mathrm{CH}$ carbons, respectively. These peaks were very much reduced in the cured sample spectra indicating substantial opening of the epoxide rings. However the residual epoxide peaks appeared somewhat larger in the thermal cure than in the microwave cure. On curing, new peaks appeared in the region 55 to $75 \mathrm{ppm}$, a broad peak at $70 \mathrm{ppm}$ and a narrower peak at $64 \mathrm{ppm}$. These were assigned to open-chain $\mathrm{CH}_{\mathrm{n}} \mathrm{O}$ and $\mathrm{CH}_{\mathrm{n}} \mathrm{N}$ groups formed by epoxide ring opening. The peak at $70 \mathrm{ppm}$ included a contribution from the glycidyl $\mathrm{CH}_{2} \mathrm{O}$ carbons. Further information relevant to the assignment of the NMR spectrum was obtained from the DD spectrum of the microwave cure shown in Figure 5(c). This technique discriminates in favour of carbons with relatively weak dipolar interactions because of either remoteness from protons (typically a quaternary carbon) or high mobility 
(typically a small end- or side-group). Comparison with the standard CP/MAS spectrum in Figure 5(a) showed that the peaks at 31, 42 and $64 \mathrm{ppm}$ were relatively more intense in the DD spectrum. By comparison with the liquid-state spectrum of PR500, the first was assigned to the $\mathrm{CH}_{3}$ carbon in component 1 . The peak at $64 \mathrm{ppm}$ was tentatively assigned from its chemical shift,to a $\mathrm{CH}_{2} \mathrm{OH}$ side-group, a possible product of the epoxy-amine reaction. This peak has a lower intensity in the spectrum obtained from microwave cure suggesting that this reaction is less prevalent in this case. The peak at $42 \mathrm{ppm}$ remained unexplained, though a small peak was observed at this chemical shift in the PR500 solution-state spectrum.

\section{Dielectric measurements}

The dielectric constant and loss factor for a range of samples with degrees of cure in the range 75 to $100 \%$ were obtained using the cavity perturbation method outlined above.

The data for conventionally and microwave cured samples are presented in figure 6. Previous work [4,14-15] has shown that when the dielectric properties are monitored during thermal cure there is an initial increase in dielectric loss factor due to the rise in temperature and this is followed by a gradual decay as the network is formed and the mobility of dipoles is hindered. It can be seen that there was no systematic difference between the dielectric properties for the microwave and thermally cured samples. There is also no difference in the properties with degree of cure over the range investigated. This is perhaps not surprising in view of the results of others and the expected form of the dielectric property versus cure cures [ref] Since other approaches used in this work show that there is a difference in the reaction path, it must be assumed that the differences this induces in the dielectric properties are smaller than the errors and that the dielectric properties are thus not sensitive to the small changes in the chemical and network nature of the cured resin.

\section{CONCLUSIONS}

The epoxy-amine reaction is more dominant in the microwave-cured samples than the other possible curing reactions including the epoxy-hydroxyl reaction. Infrared spectroscopy shows that the hydroxyl and amine bands in the thermally cured sample are more intense than in the microwave cured sample at the same degree of cure. This indicates the amine-epoxy reaction to be more dominant during microwave curing under these conditions. Solid-state NMR spectroscopy showed that there were a greater number of $-\mathrm{CH}_{2} \mathrm{OH}$ groups in the 
thermally cured sample. This group is formed in the epoxy -hydroxyl reaction and thus this reaction must be relatively more dominant during the thermal curing process. The results of the IR spectroscopy, solid state NMR and DMA all point to the same conclusion. Microwave curing under these conditions leads to enhancement of the amine-epoxy reaction compared to the epoxy-hydroxyl reaction. This leads to a different network structure as revealed by DMA. It is possible that this is responsible for the broadening of $T_{\mathrm{g}}$ commonly observed in microwave cured epoxy resins. The dielectric properties over the range of degree of cure studied are not sensitive to the state of cure or method of heating used. 


\section{REFERENCES}

1. C. Nightingale and R.J. Day, Composites A, 33, 1021 (2002)

2. I. Zainol, R.J. Day and F. Heatley, J. Appl. Polym. Sci., in press

3. I. Zainol and R.J. Day, Macromolecules, submitted

4. E. Marand, K.R. Baker and J.D. Graybeal, Macromolecules, 25, 2243 (1992)

5. J. Mijovic, A. Fishbain and J. Wijaya, Macromolecules, 25, 986 (1992)

6. C. Jordan, J. Galy and J.P. Pascault, Polym. Mater. Sci. Eng., 66, 380 (1992)

7. A. Nesbitt, D.R. Suckley and R.J. Day, in preparation

8. J.H. Wei, M.C. Hawley and J.D. Delong, Polym. Eng. Sci., 33(17), 1132 (1993)

9. R.J. Day, S.H.C. Yau and K.D. Hewson, Plast., Rubber Compos. Process. Appl., 27, 213 (1998)

10. J. Mijovic and J. Wijaya, Macromolecules, 23, 3671 (1990)

11. G.B. Portelli, W.J. Schultz, R.C. Jordan and S.C. Hackett, Int. SAMPE Tech. Conf. (1988), 20 (Mater.-Processes: Intercept. Point), pp. 20-33

12. G. Pogany, Polymer, 11, 66 (1970)

13. J.A. Brydson, Plastics Materials, Pub

14. M. Delmotte, H. Jullien and M. Ollivon, Eur. Polym. J., 4/5, 371 (1991)

15. J. Jow, M.C. Hawley, M. Finzel and T. Kern, Polym. Eng. Sci., 28, 1450 (1988) 
Table 1. Relative intensities of infrared peaks in thermally and microwave cured resin

\begin{tabular}{|l|c|c|c|}
\hline $\begin{array}{c}\text { Peak } \\
/ \mathrm{cm}^{-1}\end{array}$ & Assignment & $\begin{array}{c}\text { Relative } \\
\text { height } \\
\text { Microwav } \\
\mathrm{e}\end{array}$ & $\begin{array}{c}\text { Relative } \\
\text { height } \\
\text { Thermal }\end{array}$ \\
\hline 3552 & $\mathrm{OH}$ & 4.67 & 5.69 \\
\hline 3475 & $\mathrm{OH}$ & 6.44 & 7.65 \\
\hline 3415 & $\mathrm{OH}$ & 6.33 & 9.50 \\
\hline 3236 & $\mathrm{NH}$ & 1.67 & 1.88 \\
\hline 2963 & $\begin{array}{c}\text { aliphatic } \\
\mathrm{CH}\end{array}$ & 2.50 & 1.96 \\
\hline 2925 & aliphatic CH & 3.61 & 2.42 \\
\hline 2869 & aliphatic $\mathrm{CH}$ & 2.61 & 2.00 \\
\hline 2854 & & 2.33 & 1.50 \\
\hline 3062 & aromatic CH & 0.89 & 0.88 \\
\hline 3036 & aromatic CH & 1.00 & 1.00 \\
\hline
\end{tabular}




\section{Figure captions}

Figure 1 Glass transition temperature, measured by MDSC, as a function of cure for microwave and thermally cured samples.

Figure 2 Difference between onset and endset temperatures as a function of degree of cure for microwave cured () and thermally cured () samples.

Figure 3 Dynamic mechanical analysis results for the real and imaginary parts of the flexural modulus and the loss tangent for microwave, fig $3 a$, and thermally cured, fig $3 b$, resin

Figure 4 FTIR spectra of thermally and microwave cured samples. The degree of cure was $90 \%$. The spectrum of the microwave cured sample has been displaced upwards by $10 \%$ for clarity.

Figure 5. ${ }^{13} \mathrm{C}$ CP/MAS NMR spectra of PR500 resins. (a) thermal cure; (b) microwave cure; (c) DD spectrum of microwave cure. The spinning rate was $4.3 \mathrm{kHz}$ for all spectra. Figures (b) and (c) have been plotted on the same vertical scale. The label $s$ indicates a CSA spinning sideband; a sideband of the aromatic peak at $128 \mathrm{ppm}$ underlies the peak at $64 \mathrm{ppm}$.

Figure 6. Variation of (a) loss tangent, $\tan \delta$ and (b) dielectric constant with degree of cure for microwave and thermally cured samples. 


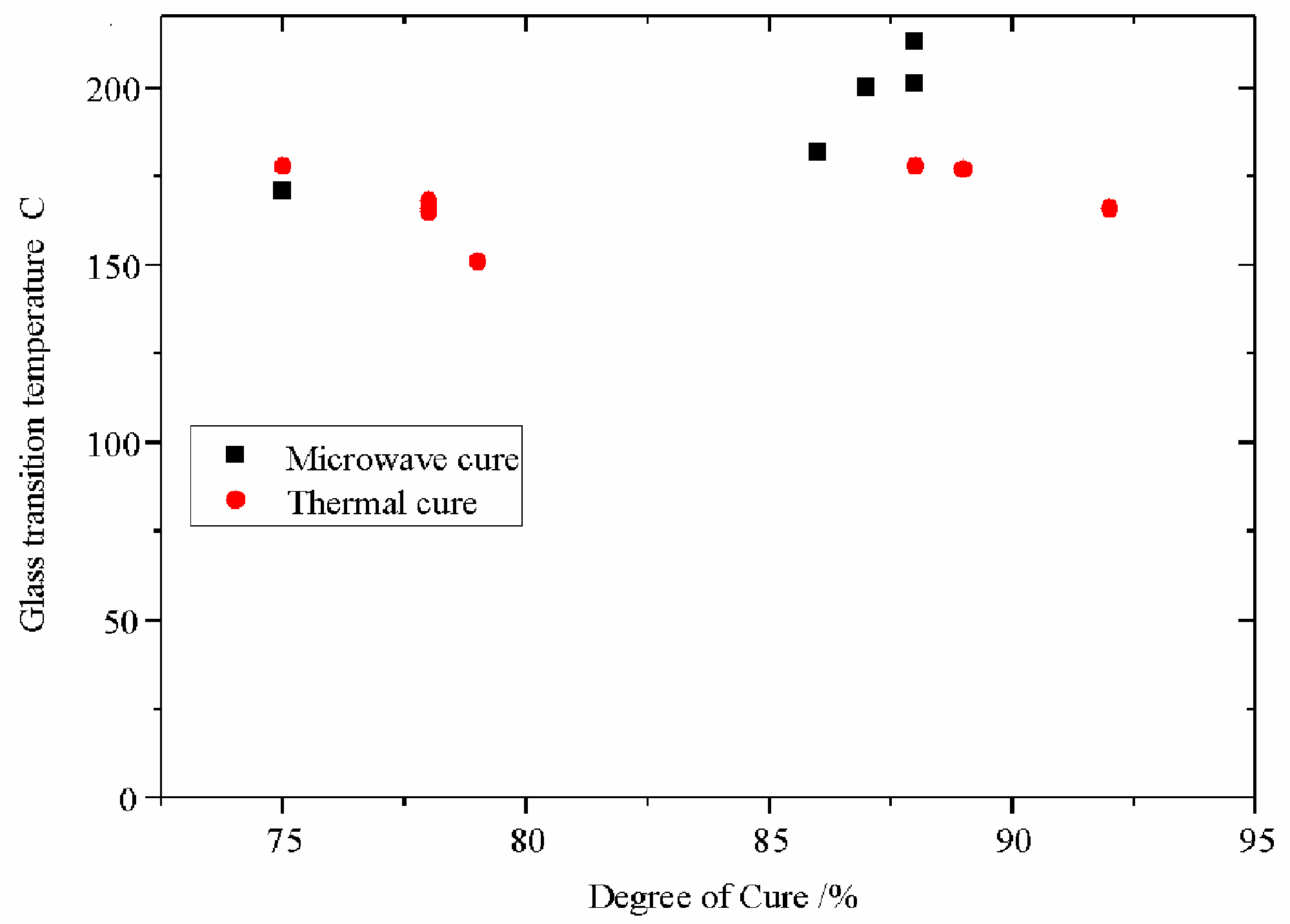

Figure 1 


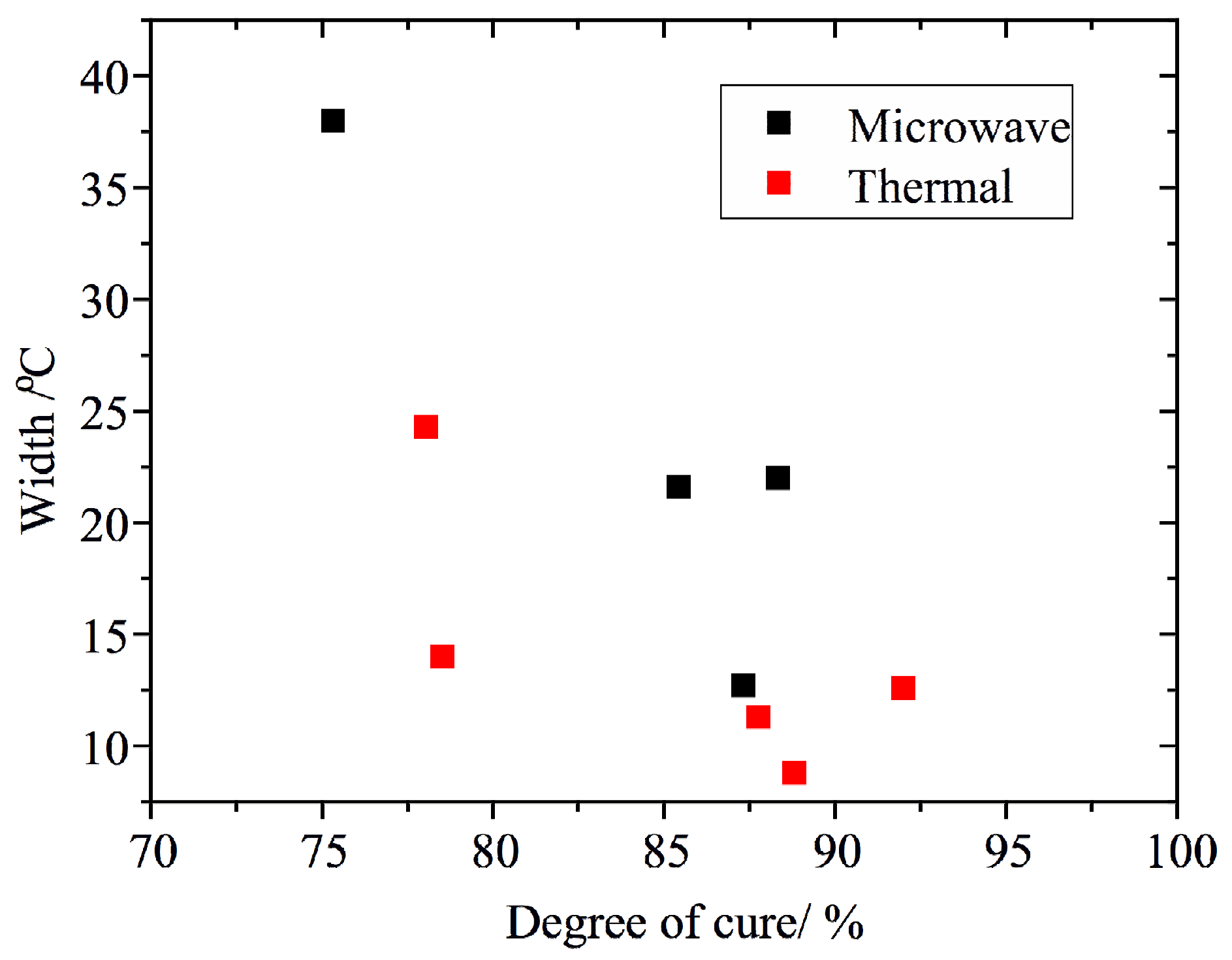

Figure 2 


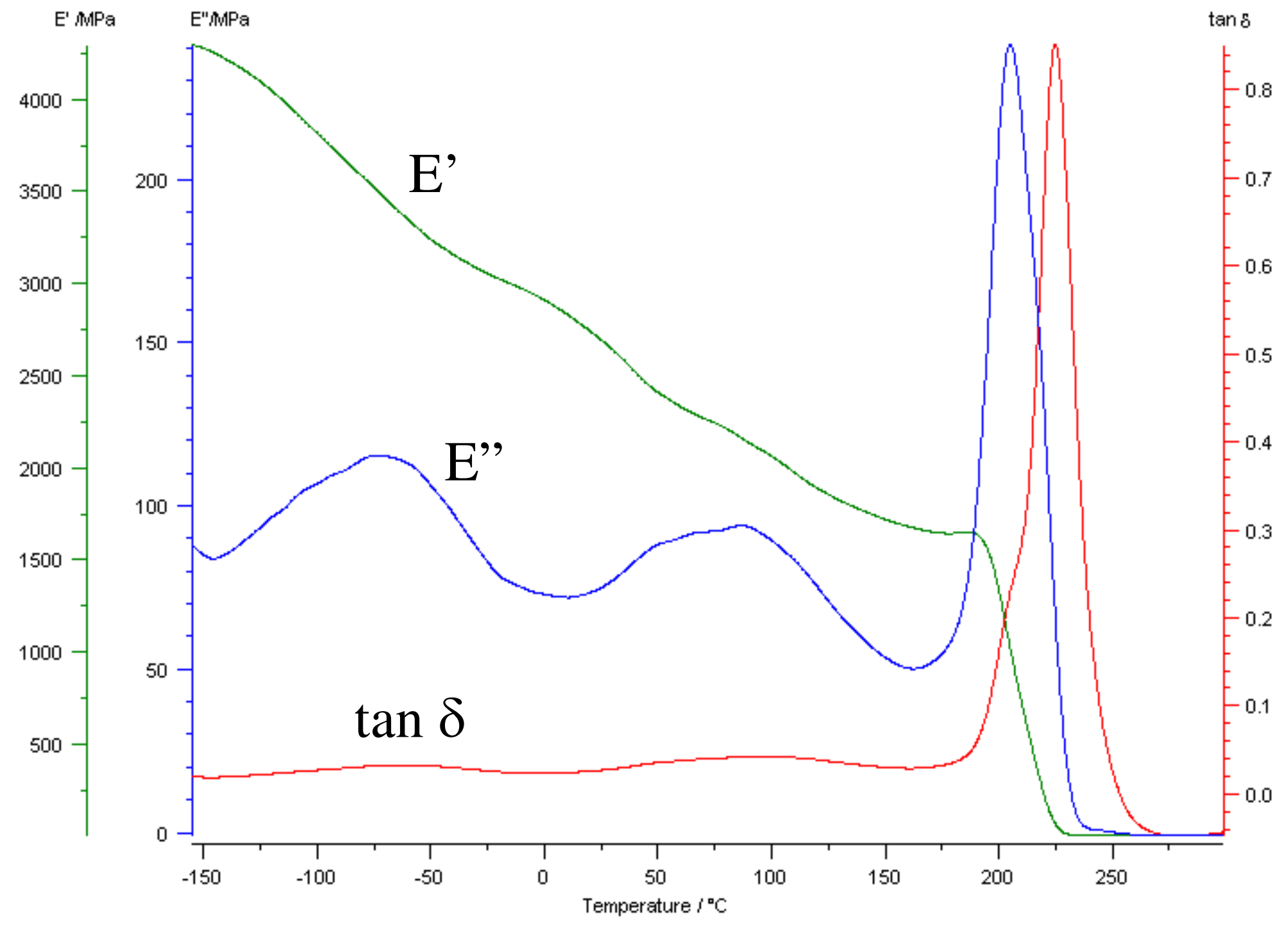

Figure 3 a 


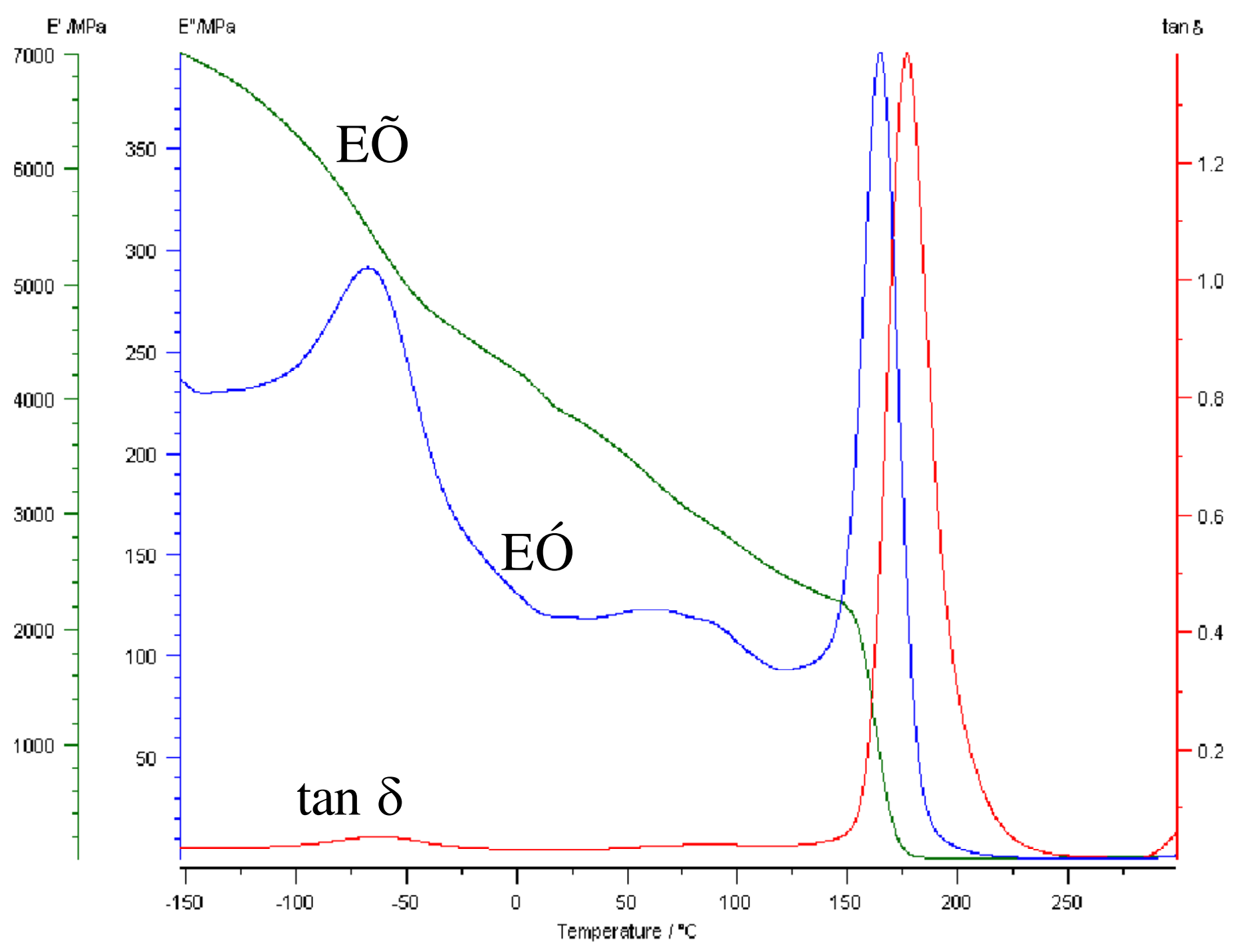

Figure $3 b$ 


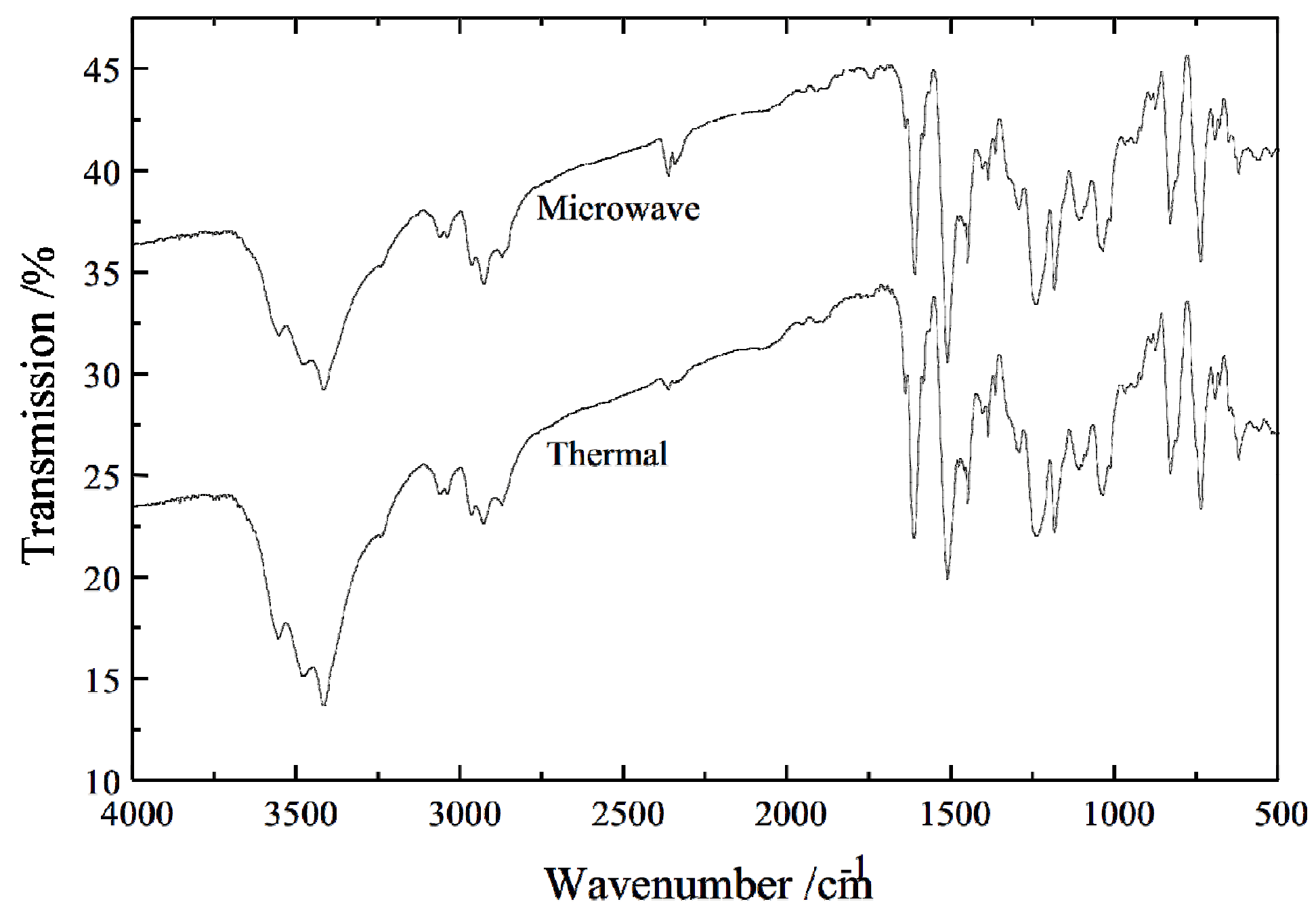

Figure 4 


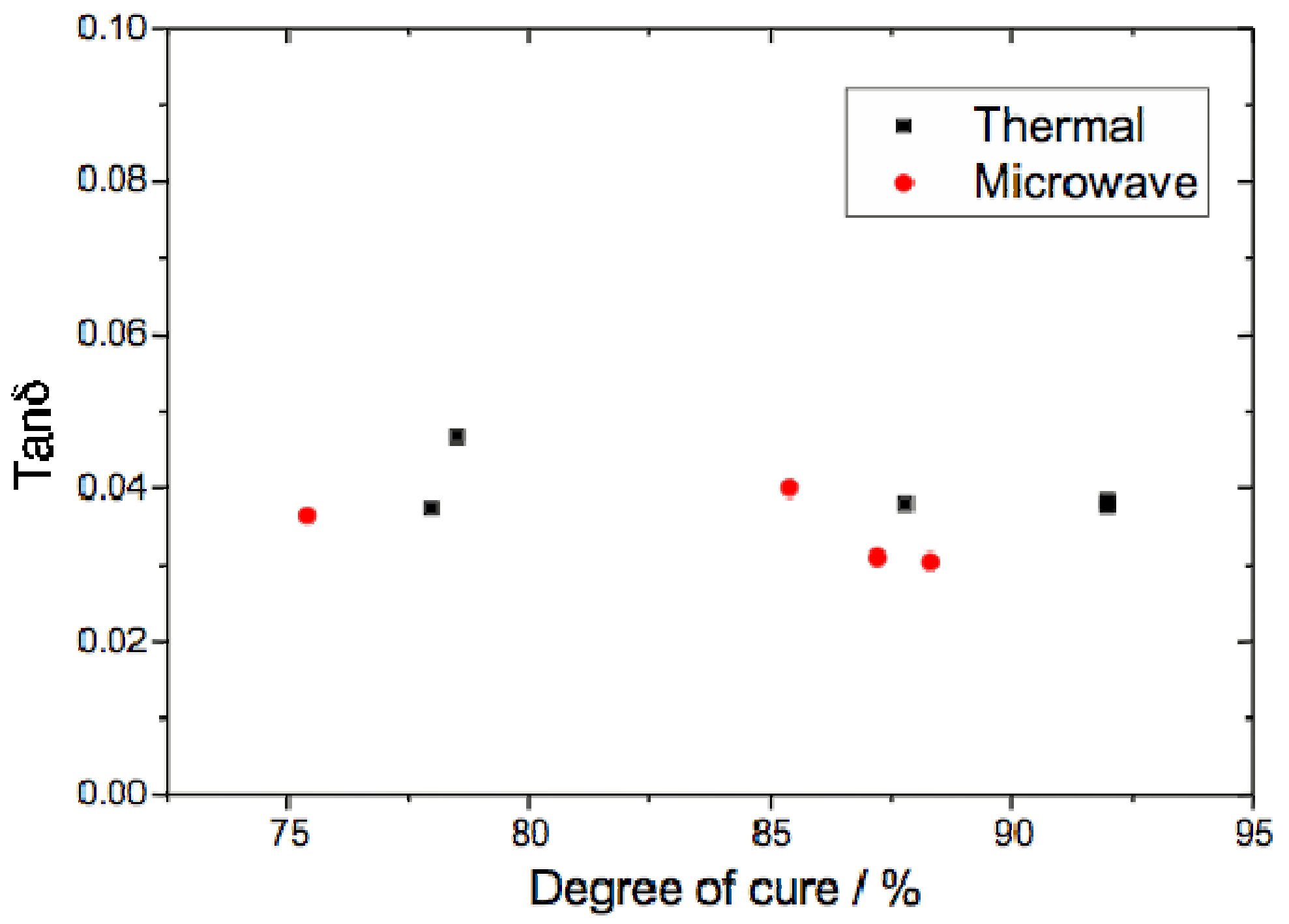

Figure 6a 


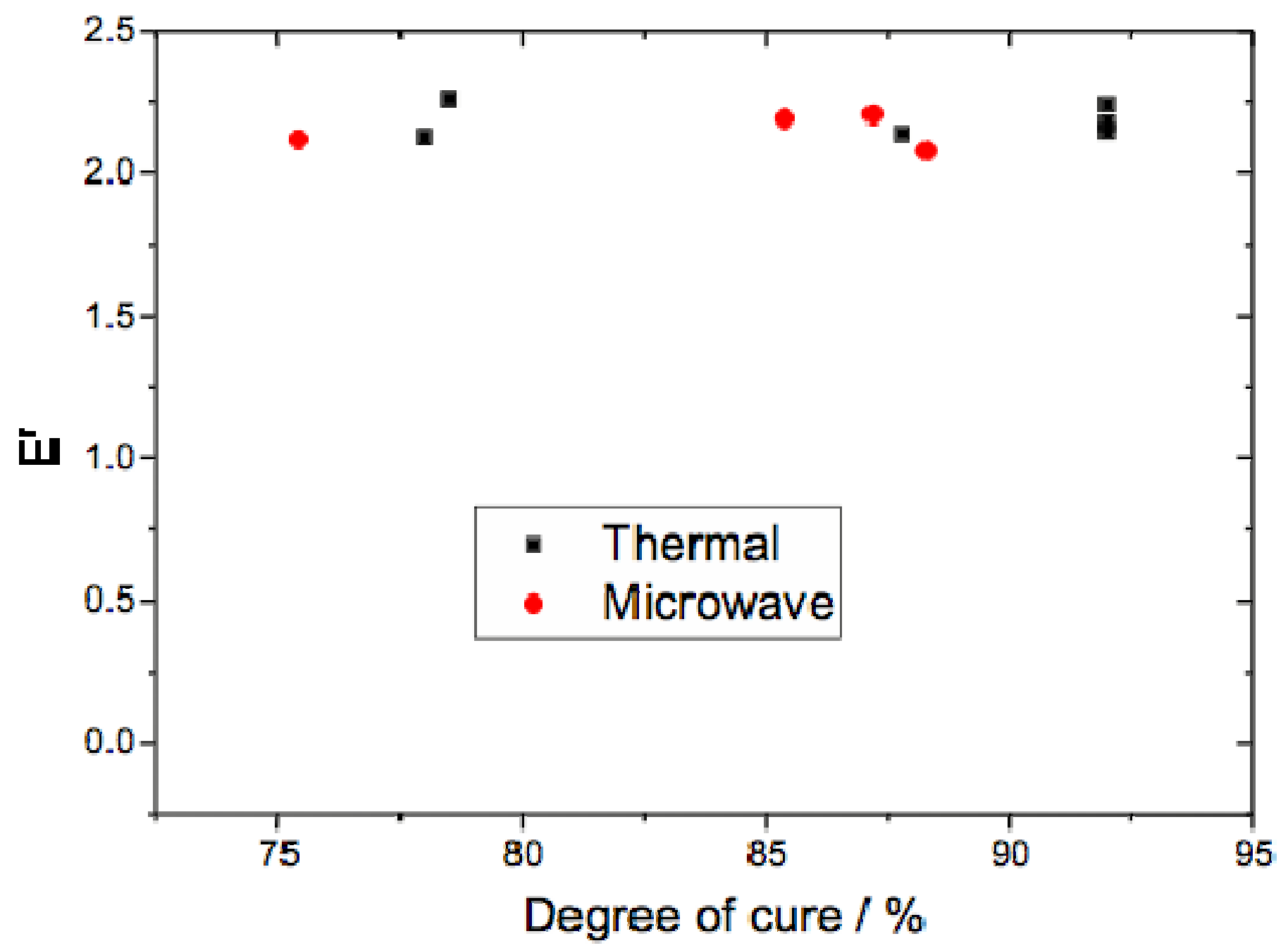

Figure $6 b$ 

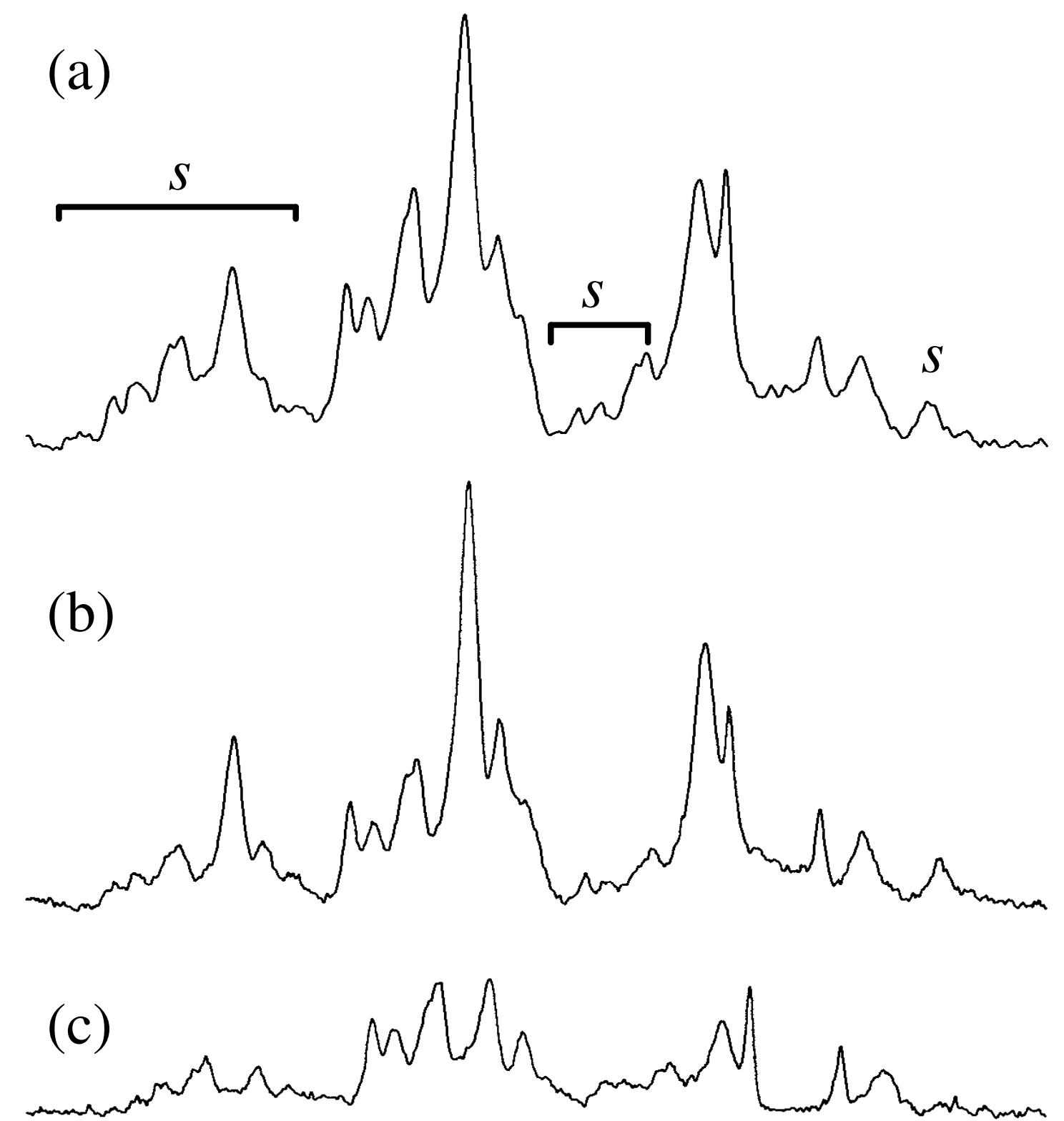

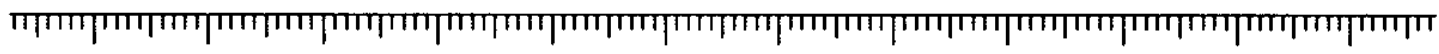
$\begin{array}{llllllll}200 & 160 & 120 & 80 & 60 & 40 & 20 & \text { ppm }\end{array}$

Figure 5 